\title{
Synthesis of poly(sulfonate ester)s by ADMET polymerization
}

\author{
Rebecca R. Parkhurst, ${ }^{a}$ Sandor Balog, ${ }^{a}$ Christoph Weder, ${ }^{a}$ and Yoan C. Simon $*^{a}$
}

\begin{abstract}
Many hydrocarbon polymers containing heteroatom defects in the main chain have been investigated as degradable polyethylene-like materials, including aliphatic polyesters. Here, acyclic diene metathesis (ADMET) polymerization was used for the synthesis of aliphatic poly(sulfonate ester)s. The requisite sulfonate ester containing $\alpha, \omega$-diene monomers with varying numbers of methylene groups were synthesized, and their polymerization in the presence of ruthenium-N-heterocyclic (Ru-NHC) alkylidene catalysts was studied. A clear negative neighboring group effect (NNGE) was observed for shorter dienes, either inhibiting polymerization or resulting in low-molecular-weight oligomers. The effect was absent when undec-10-en-1-yl undec-10-ene-1-sulfonate was employed as the monomer, and its ADMET polymerization afforded polymers with appreciable number-average molecular weights of up to $37,000 \mathrm{~g} / \mathrm{mol}$ and a dispersity $\oslash$ of 1.8 . These polymers were hydrogenated to afford the desired polyethylene-like systems. The thermal and morphological properties of both saturated and unsaturated polymers were investigated. The incorporation of sulfonate ester groups in the polymer backbone offers an interesting alternative to other heteroatoms and helps further the understanding of the effects of these defects on the overall polymer properties.
\end{abstract}

\section{Introduction}

Since the advent of the Ziegler-Natta process in the early $1950 \mathrm{~s},{ }^{1}$ polyolefins, and particularly polyethylene, have become ubiquitous in applications that range from packaging, ${ }^{2,3}$ to implants, ${ }^{4}$ to life vests. ${ }^{5}$ Polyethylene exhibits tailorable mechanical properties, low cost, and high chemical and biological stability. However, in the light of the high rates of polyethylene production and use, high durability also contributes to its accumulation as waste in the environment due to its extremely slow biodegradation. Therefore, there has been great interest in producing "degradable" polyethylene, i.e. polyethylene-like polymers containing defects that facilitate their breakdown into low-molecular-weight fragments that are more easily digested by micro-organisms. The main methods through which this has been accomplished thus far have been the introduction of unsaturated carbon-carbon bonds, weak sites such as ketones in both side and main chains, or other cleavable groups such as disulfides ${ }^{6}$ or esters. ${ }^{7}$

Polyesters such as poly(lactic acid) and polyhydroxyalkanoates are therefore often mentioned as environmentally benign alternatives to the use of polyolefins. ${ }^{8,9}$ Numerous reports have also investigated long-chain aliphatic polyesters to model the effect of these hydrolyzable defects on the crystal packing of the polyethylene-like material and consequently its bulk properties. ${ }^{10-13}$ Despite recent interest in such polyesters, the corresponding poly(sulfonate ester)s have not yet been explored. Sulfonate esters have the potential to serve as a useful point of degradation as they are susceptible to both thermolysis $^{14}$ and hydrolysis ${ }^{15}$ (Scheme S1, Supporting Information).

Here, we report the use of acyclic diene metathesis (ADMET) as an appealing technique for the synthesis of degradable, polyethylene-like poly(sulfonate ester)s that contain sulfonate ester groups in the backbone. Through polycondensation of $\alpha, \omega$-dienes, ADMET polymerization allows access to a wide variety of both linear and hyperbranched polyolefins with unmatched architectural regularity (Scheme 1a). ${ }^{16,17}$ The development of a wide variety of catalysts for this transformation, particularly the later generation Ru-NHC alkylidene catalysts, has expanded its functional group tolerance (Scheme 1b). ${ }^{18,19}$ Unlike the related ring-opening metathesis polymerization (ROMP), which is a chain-growth process driven by the release of ring strain, ADMET is driven by the removal of the ethylene gas generated as a by-product. ADMET chemistry has been used recently in the synthesis of both all-carbon polyolefins ${ }^{20-22}$ as well as polyethylene-like polymers containing heteroatoms ${ }^{23-29}$ or aromatic rings $\mathrm{s}^{30-32}$ in the main chain.

ADMET offers an interesting alternative for the incorporation of aliphatic sulfonate esters into the polymer backbone, which are rare in the literature. The polycondensation of disulfonyl chlorides with diphenols has been used in the synthesis of aromatic poly(sulfonate ester)s which possess interesting physical, chemical, electrical and thermal properties. ${ }^{33,34}$ However, the number-average molecular weights of the resulting polymers tend to be rather low (ranging from 2,000 to $16,000 \mathrm{~g} / \mathrm{mol}$ ) and the dispersities high (up to 29). These conditions also often require a phasetransfer catalyst and produce stoichiometric amounts of salt byproducts. To the best of our knowledge, the only example of aliphatic poly(sulfonate ester)s to date have been synthesized by the ring-opening polymerization of 1,3-propanesultone. ${ }^{35}$ The present strategy allows access to new polyethylene-like materials, ${ }^{36}$ which exhibit properties complementing the range of characteristics covered by previously available materials. 
a)

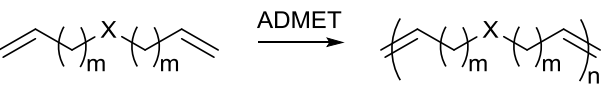

b)

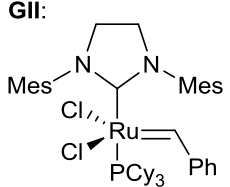

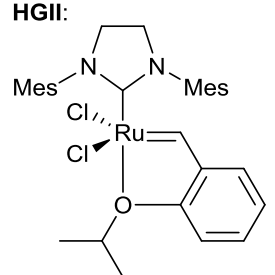

Scheme 1 a) ADMET polymerization of $\alpha, \omega$-dienes and b) structures of Grubbs catalyst $2^{\text {nd }}$ generation (GII) and Hoveyda-Grubbs catalyst $2^{\text {nd }}$ generation (HGII).

\section{Experimental Section}

\section{Materials and Methods}

All commercially available chemicals were used as received without further purification. 1-Bromo-6-hexene, 5-hexen-1-ol, 11-bromo-1-undecene, and oxalyl chloride $\left((\mathrm{COCl})_{2}\right)$ were purchased from ABCR, and 11-undecen-1-ol was purchased from TCI Chemicals. High density polyethylene (HDPE) was received from DSM (Stamylan 7048). All other chemicals were purchased from Sigma-Aldrich. Dimethylformamide (DMF) was dried by passing the solvent through alumina columns. A Biotage ${ }^{\circledR I s o l e r a O n e}$ with pre-packed silica gel columns was employed for flash column chromatography. Monomer M1 was synthesized according to the procedure reported by Le Flohic et al. ${ }^{37}$ Microwave reactions were performed on a Biotage ${ }^{\circledR}$ Initator Microwave Synthesizer.

${ }^{1} \mathrm{H}$ and ${ }^{13} \mathrm{C}$ NMR spectra were measured on a Bruker Avance spectrometer at either $360 \mathrm{MHz}\left({ }^{1} \mathrm{H}\right)$ and $90 \mathrm{MHz}$ $\left({ }^{13} \mathrm{C}\right)$, or $500 \mathrm{MHz}\left({ }^{1} \mathrm{H}\right)$ and $125 \mathrm{MHz}\left({ }^{13} \mathrm{C}\right)$ as noted. All spectra were recorded in $\mathrm{CDCl}_{3}$, and chemical shifts $(\delta)$ are reported in parts per million ( $\mathrm{ppm}$ ) referenced to the residual solvent peak (7.27 ppm and $77.0 \mathrm{ppm}$, respectively). Infrared (IR) spectra were recorded on a PerkinElmer Spectrum 65 FTIR Spectrometer using attenuated total reflection (ATR) sampling.

Mass spectrometry (MS) data for small molecules were provided by the analytical services at the University of Fribourg Chemistry Department using either electrospray ionization (ESI), electron ionization (EI), or matrix-assisted laser desorption/ionization (MALDI). Polymer molecular weights were measured by gel permeation chromatography (GPC, 40 ${ }^{\circ} \mathrm{C}, 1 \mathrm{~mL} / \mathrm{min}$ ) in $\mathrm{CHCl}_{3}$ unless otherwise noted, and are reported versus polystyrene standards. A Polymer Laboratories $5 \mu \mathrm{m}$ mixed-C guard column and two GPC columns were employed with an Agilent Technologies series 1200 HPLC instrument. Wyatt Technology Corp. provided both the detector (Optilab REX interferometric refractometer) and software (ASTRA) for analysis.

Thermogravimetric analysis (TGA) was performed using a Mettler-Toledo STAR thermogravimetric analyzer under $\mathrm{N}_{2}$ with a heating rate of $10{ }^{\circ} \mathrm{C} / \mathrm{min}$. Differential scanning calorimetry (DSC) measurements were conducted on a MettlerToledo STAR instrument. These experiments were done under $\mathrm{N}_{2}$ with heating/cooling rates of $10{ }^{\circ} \mathrm{C} / \mathrm{min}$ for the specified temperature range. Dynamic mechanical analysis ${ }^{38}$ was performed with a TA Instruments DMA Q 800 under $\mathrm{N}_{2}$. The heating rate employed was $3{ }^{\circ} \mathrm{C} / \mathrm{min}$, ranging from $-100{ }^{\circ} \mathrm{C}$ to the melting point of the sample. Films of $\mathbf{P 3}$ for thermomechanical analysis were solution cast from $\mathrm{PhCH}_{3}$ at $30{ }^{\circ} \mathrm{C}$.

Small- and wide-angle X-ray scattering (SAXS and WAXS, respectively) spectra were recorded by a NanoMax-IQ camera (Rigaku Innovative Technologies, Auburn Hills, MI USA). Samples were kept at room temperature in vacuum during the measurements. Raw data were processed according to standard procedures, and the isotropic scattering spectra are presented as a function of the momentum transfer $\mathrm{q}=4 \pi \cdot \lambda^{-1} \cdot \sin (\theta / 2)$, where $\theta$ is the scattering angle and $\lambda=0.1524 \mathrm{~nm}$ is the photon wavelength. Films of HDPE, P3 and HP3 for SAXS/WAXS analysis were prepared by meltprocessing and quenching in iced water (HDPE) or by placing the freshly melted samples in a freezer $\left(-20^{\circ} \mathrm{C}\right)(\mathbf{P 3} / \mathbf{H P 3})$.

\section{Synthesis of hex-5-en-1-yl hex-5-ene-1-sulfonate (M2)}

Hex-5-ene-1-sulfonyl chloride (2) 1-Bromo-6-hexene $(500 \mathrm{mg}$, $3.07 \mathrm{mmol})$ and sodium sulfite $\left(\mathrm{Na}_{2} \mathrm{SO}_{3}, 560 \mathrm{mg}, 4.45 \mathrm{mmol}\right)$ were combined in water $(4.0 \mathrm{~mL})$. The mixture was heated to reflux overnight with stirring. After cooling to room temperature, water was removed under reduced pressure. The resulting white solid was taken up in phosphorus(V) oxychloride $\left(\mathrm{POCl}_{3}, 4.0 \mathrm{~mL}\right)$, fitted with a reflux condenser, and flushed with $\mathrm{N}_{2}$ for $10 \mathrm{~min}$. After heating to $120{ }^{\circ} \mathrm{C}$ for $100 \mathrm{~min}$, the reaction was cooled to room temperature. The reaction mixture was then poured over ice and the $\mathrm{POCl}_{3}$ was allowed to hydrolyze for $1 \mathrm{~h}$. The aqueous layer was extracted with dichloromethane $\left(\mathrm{CH}_{2} \mathrm{Cl}_{2}, 2 \times 25 \mathrm{~mL}\right)$. The combined organic layers were dried over anhydrous sodium sulfate $\left(\mathrm{Na}_{2} \mathrm{SO}_{4}\right)$, filtered, and the solvent was removed under reduced pressure. The crude product was purified by flash column chromatography $\left(1: 3 \mathrm{CH}_{2} \mathrm{Cl}_{2}\right.$ :Hexane, $\mathrm{R}_{\mathrm{f}}=$ 0.25 ) to yield 2 as a yellowish oil $(356 \mathrm{mg}, 64 \%) .{ }^{1} \mathrm{H}$ NMR (360 $\left.\mathrm{MHz}, \mathrm{CDCl}_{3}\right), \delta(\mathrm{ppm}): 5.78\left(\mathrm{~m}, 1 \mathrm{H}, \mathrm{CH}=\mathrm{CH}_{2}\right), 5.04(\mathrm{~m}, 2 \mathrm{H}$, $\left.\mathrm{CH}=\mathrm{CH}_{2}\right), 3.69\left(\mathrm{~m}, 2 \mathrm{H}, \mathrm{CH}_{2}-\mathrm{SO}_{2} \mathrm{Cl}\right), 2.10\left(\mathrm{~m}, 4 \mathrm{H}, \mathrm{CH}_{2}-\mathrm{CH}=, \mathrm{CH}_{2}-\right.$ $\left.\mathrm{CH}_{2} \mathrm{SO}_{2} \mathrm{Cl}\right), 1.60\left(\mathrm{~m}, 2 \mathrm{H}, \mathrm{CH}_{2}-\mathrm{CH}_{2} \mathrm{CH}=\right) .{ }^{13} \mathrm{C} \mathrm{NMR}(90 \mathrm{MHz}$, $\left.\mathrm{CDCl}_{3}\right), \delta(\mathrm{ppm}): 137.0\left(\mathrm{CH}=\mathrm{CH}_{2}\right), 115.9\left(\mathrm{CH}=\mathrm{CH}_{2}\right), 65.2\left(\mathrm{CH}_{2}-\right.$ $\left.\mathrm{SO}_{2} \mathrm{Cl}\right), 32.8\left(\mathrm{CH}_{2}-\mathrm{CH}=\right), 26.6\left(\mathrm{CH}_{2}-\mathrm{CH}_{2} \mathrm{SO} \mathrm{O}_{2} \mathrm{Cl}\right), 23.6\left(\mathrm{CH}_{2}-\right.$ $\left.\mathrm{CH}_{2} \mathrm{CH}=\right)$. MS (MALDI): $\mathrm{m} / z\left([\mathrm{M}-\mathrm{H}]^{-}\right)=181.06$.

Hex-5-en-1-yl hex-5-ene-1-sulfonate (M2) 5-Hexen-1-ol, 4dimethylaminopyridine (DMAP), and triethylamine $\left(\mathrm{Et}_{3} \mathrm{~N}\right)$ were dissolved in $\mathrm{CH}_{2} \mathrm{Cl}_{2}$ and cooled to $0{ }^{\circ} \mathrm{C}$ in an ice/water bath. Compound 2 was then added drop-wise and the reaction mixture was stirred for $75 \mathrm{~min}$. The reaction mixture was allowed to cool then washed with water, $1 \mathrm{~N} \mathrm{HCl}$, and $\mathrm{NaHCO}_{3(\mathrm{aq})}(15 \mathrm{~mL}$ each). The organic layer was dried over magnesium sulfate $\left(\mathrm{MgSO}_{4}\right)$, filtered, and the solvent was removed under reduced pressure. The crude product was purified by flash column chromatography (1:1 $\mathrm{CH}_{2} \mathrm{Cl}_{2}$ :Hexane, $\left.\mathrm{R}_{\mathrm{f}}=0.18\right)$ to yield $\mathbf{M 2}$ as a colorless oil $(326 \mathrm{mg}$, $88 \%) .{ }^{1} \mathrm{H}$ NMR $\left(360 \mathrm{MHz}, \mathrm{CDCl}_{3}\right), \delta(\mathrm{ppm}): 5.78(\mathrm{~m}, 2 \mathrm{H}$, $\left.\mathrm{CH}=\mathrm{CH}_{2}\right), 5.02\left(\mathrm{~m}, 4 \mathrm{H}, \mathrm{CH}=\mathrm{CH}_{2}\right), 4.22\left(\mathrm{t}, J=7.2 \mathrm{~Hz}, 2 \mathrm{H}, \mathrm{CH}_{2}-\right.$ $\left.\mathrm{OSO}_{2}\right), 3.10\left(\mathrm{~m}, 2 \mathrm{H}, \mathrm{CH}_{2}-\mathrm{SO}_{2}-\mathrm{O}\right) 2.11\left(\mathrm{~m}, 4 \mathrm{H}, \mathrm{CH}_{2}-\mathrm{CH}=\right), 1.85$ $\left(\mathrm{m}, 2 \mathrm{H}, \mathrm{CH}_{2}-\mathrm{CH}_{2} \mathrm{OSO}_{2}\right), 1.74\left(\mathrm{~m}, 2 \mathrm{H}, \mathrm{CH}_{2}-\mathrm{CH}_{2} \mathrm{SO}_{2}-\mathrm{O}\right), 1.53(\mathrm{~m}$, $\left.4 \mathrm{H}, \mathrm{CH}_{2}-\mathrm{CH}_{2} \mathrm{CH}=\right) .{ }^{13} \mathrm{C} \mathrm{NMR}\left(90 \mathrm{MHz}, \mathrm{CDCl}_{3}\right), \delta$ (ppm): 137.9 $\left(\mathrm{CH}=\mathrm{CH}_{2}\right), 137.5\left(\mathrm{CH}=\mathrm{CH}_{2}\right), 115.4\left(\mathrm{CH}=\mathrm{CH}_{2}\right), 115.2\left(\mathrm{CH}=\mathrm{CH}_{2}\right)$, $69.4\left(\mathrm{CH}_{2}-\mathrm{OSO}_{2}\right), 50.2\left(\mathrm{CH}_{2}-\mathrm{SO}_{2}-\mathrm{O}\right), 33.0\left(2 \times \mathrm{CH}_{2}-\mathrm{CH}=\right), 28.6$ $\left(\mathrm{CH}_{2}-\mathrm{CH}_{2} \mathrm{OSO}_{2}\right), 27.3\left(\mathrm{CH}_{2}-\mathrm{CH}_{2} \mathrm{SO}_{2}-\mathrm{O}\right), 24.6\left(\mathrm{CH}_{2}-\mathrm{CH}_{2} \mathrm{CH}=\right)$, $22.9\left(\mathrm{CH}_{2}-\mathrm{CH}_{2} \mathrm{CH}=\right)$. MS (ESI): $m / z\left([\mathrm{M}+\mathrm{Na}]^{+}\right)=269.1$.

\section{Synthesis of undec-10-en-1-yl undec-10-ene-1-sulfonate (M3)}

Undec-10-ene-1-sulfonyl chloride (3) 11-Bromo-1-undecene ( $1.000 \mathrm{~g}, 4.29 \mathrm{mmol})$ and $\mathrm{Na}_{2} \mathrm{SO}_{3}(865 \mathrm{mg}, 6.86 \mathrm{mmol})$ were combined in tetrahydrofuran (THF, $4.0 \mathrm{~mL})$, ethanol $(\mathrm{EtOH}$, 
$8.0 \mathrm{~mL})$, and water $(8.0 \mathrm{~mL})$ in a microwave vial. After $5 \mathrm{~min}$ of pre-stirring, the mixture was microwaved for $30 \mathrm{~min}$ at 160 ${ }^{\circ} \mathrm{C}$. The solvent was then removed under reduced pressure and the residue was further dried at $60{ }^{\circ} \mathrm{C}$ in a vacuum oven overnight. The resulting white solid was suspended in cold $(\mathrm{COCl})_{2}$ and stirred at $0{ }^{\circ} \mathrm{C}$ under $\mathrm{N}_{2}$ for $30 \mathrm{~min}$. The suspension was then warmed to room temperature. DMF was added drop-wise and the reaction mixture was stirred for $3 \mathrm{~h}$. The solvent was then removed by distillation. The remaining solid was taken up in diethyl ether $\left(\mathrm{Et}_{2} \mathrm{O}, 50 \mathrm{~mL}\right)$, filtered, and the filtrate was washed with $\mathrm{Et}_{2} \mathrm{O}(50 \mathrm{~mL})$. The combined organic layers were concentrated under reduced pressure. The crude product was purified by flash column chromatography two times $\left(1: 3 \mathrm{CH}_{2} \mathrm{Cl}_{2}\right.$ :Hexane, $\left.\mathrm{R}_{\mathrm{f}}=0.28\right)$ to yield $\mathbf{3}$ as a colorless oil (1.043 g, 24\%). ${ }^{1} \mathrm{H}$ NMR (500 $\left.\mathrm{MHz}, \mathrm{CDCl}_{3}\right), \delta$ (ppm): $5.81\left(\mathrm{~m}, 1 \mathrm{H}, \mathrm{CH}=\mathrm{CH}_{2}\right), 4.97\left(\mathrm{~m}, 2 \mathrm{H}, \mathrm{CH}=\mathrm{CH}_{2}\right), 3.67$ $\left(\mathrm{m}, 2 \mathrm{H}, \quad \mathrm{CH}_{2}-\mathrm{SO}_{2} \mathrm{Cl}\right), 2.05\left(\mathrm{~m}, 4 \mathrm{H}, \quad \mathrm{CH}_{2}-\mathrm{CH}=, \mathrm{CH}_{2}-\right.$ $\left.\mathrm{CH}_{2} \mathrm{SO}_{2} \mathrm{Cl}\right), 1.50\left(\mathrm{~m}, 2 \mathrm{H}, \mathrm{CH}_{2}-\mathrm{CH}_{2} \mathrm{CH}=\right), 1.40-1.26(\mathrm{~m}, 10 \mathrm{H}$,

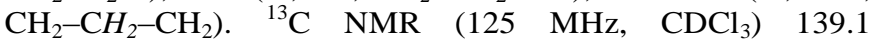
$\left(\mathrm{CH}=\mathrm{CH}_{2}\right), 114.2\left(\mathrm{CH}=\mathrm{CH}_{2}\right), 65.4\left(\mathrm{CH}_{2}-\mathrm{SO}_{2} \mathrm{Cl}\right), 33.7\left(\mathrm{CH}_{2}-\right.$ $\mathrm{CH}=), 29.2,29.1,29.0,28.9,28.8,27.6,24.2\left(\mathrm{CH}_{2}-\mathrm{CH}_{2}-\mathrm{CH}_{2}\right)$. MS (EI): $m / z\left(\mathbf{M}^{+}\right)=252.11$.

Undec-10-en-1-yl undec-10-ene-1-sulfonate (M3) 10Undecen-1-ol (0.64 mL, $3.18 \mathrm{mmol})$, DMAP (39 mg, 0.32 $\mathrm{mmol})$, and $\mathrm{Et}_{3} \mathrm{~N}(0.53 \mathrm{~mL}, 3.82 \mathrm{mmol})$ were combined in $\mathrm{CH}_{2} \mathrm{Cl}_{2}(20 \mathrm{~mL})$ and cooled to $0{ }^{\circ} \mathrm{C}$ in an ice/water bath with stirring. A solution of compound $3(965 \mathrm{mg}, 3.82 \mathrm{mmol})$ in $\mathrm{CH}_{2} \mathrm{Cl}_{2}(10 \mathrm{~mL})$ was then added drop-wise to the reaction mixture. The reaction mixture was stirred at $0{ }^{\circ} \mathrm{C}$ for $30 \mathrm{~min}$, allowed to warm to room temperature, and washed with water, $1 \mathrm{~N} \mathrm{HCl}$, and brine (25 mL each). The organic layer was dried over $\mathrm{MgSO}_{4}$, filtered, and the solvent was removed under reduced pressure. The crude product was purified by flash column chromatography $\left(1: 4 \mathrm{CH}_{2} \mathrm{Cl}_{2}:\right.$ Hexane, $\left.\mathrm{R}_{\mathrm{f}}=0.21\right)$ to yield M3 as a colorless oil (789 mg, 64\%). ${ }^{1} \mathrm{H}$ NMR (500 MHz, $\left.\mathrm{CDCl}_{3}\right), \delta(\mathrm{ppm}): 5.82\left(\mathrm{~m}, 2 \mathrm{H}, \mathrm{CH}=\mathrm{CH}_{2}\right), 4.98(\mathrm{~m}, 4 \mathrm{H}$, $\left.\mathrm{CH}=\mathrm{CH}_{2}\right), 4.21\left(\mathrm{t}, \mathrm{J}=5.0 \mathrm{~Hz}, 2 \mathrm{H}, \mathrm{CH}_{2}-\mathrm{OSO}_{2}\right), 3.08(\mathrm{~m}, 2 \mathrm{H}$, $\left.\mathrm{CH}_{2}-\mathrm{SO}_{2}-\mathrm{O}\right) 2.05\left(\mathrm{~m}, 4 \mathrm{H}, \mathrm{CH}_{2}-\mathrm{CH}=\right), 1.84\left(\mathrm{~m}, 2 \mathrm{H}, \mathrm{CH}_{2}-\right.$ $\left.\mathrm{CH}_{2} \mathrm{OSO}_{2}\right), 1.71\left(\mathrm{~m}, 2 \mathrm{H}, \mathrm{CH}_{2}-\mathrm{CH}_{2} \mathrm{SO}_{2}-\mathrm{O}\right), 1.45-1.29(\mathrm{~m}, 24 \mathrm{H}$, $\left.\mathrm{CH}_{2}-\mathrm{CH}_{2}-\mathrm{CH}_{2}\right) .{ }^{13} \mathrm{C}$ NMR $\left(125 \mathrm{MHz}, \mathrm{CDCl}_{3}\right), \delta(\mathrm{ppm}): 139.2$ $\left(\mathrm{CH}=\mathrm{CH}_{2}\right), \quad 139.1 \quad\left(\mathrm{CH}=\mathrm{CH}_{2}\right), \quad 114.17 \quad\left(\mathrm{CH}=\mathrm{CH}_{2}\right), \quad 114.15$ $\left(\mathrm{CH}=\mathrm{CH}_{2}\right), 69.7\left(\mathrm{CH}_{2}-\mathrm{OSO}_{2}\right), 50.4\left(\mathrm{CH}_{2}-\mathrm{SO}_{2}-\mathrm{O}\right), 33.8(2 \times$ $\left.\mathrm{CH}_{2}-\mathrm{CH}=\right)$, 29.35, 29.33, 29.31, 29.20, 29.18, 29.05, 29.01, 29.00, 28.96, 28.87, 28.85, 28.2, 25.4, $23.5\left(\mathrm{CH}_{2}-\mathrm{CH}_{2}-\mathrm{CH}_{2}\right)$. MS (ESI): $m / z\left([\mathrm{M}+\mathrm{Na}]^{+}\right)=409.3$.

\section{Polymer Synthesis}

General procedure for bulk polymerization A $10-\mathrm{mL}$ Schlenk flask was charged with monomer and flushed with $\mathrm{N}_{2}$ for $20 \mathrm{~min}$. The chosen Ru-NHC alkylidene catalyst (1 mol \%) was added under $\mathrm{N}_{2}$ to the stirred monomer, and the reaction vessel was placed under dynamic vacuum ( 0.01-0.1 mbar) at room temperature. The evolution of a gas could immediately be observed. After $2.5 \mathrm{~h}$ bubbling had slowed and the temperature was then slowly raised to $80{ }^{\circ} \mathrm{C}$. The reaction mixture was stirred at this temperature overnight. The reaction mixture was subsequently cooled to room temperature and dissolved in a minimal volume of a 1:99 v/v mixture of ethyl vinyl ether and toluene $\left(\mathrm{PhCH}_{3}\right)$. The polymer was then precipitated in cold methanol $(\mathrm{MeOH})$ and collected by vacuum filtration to yield the desired polymer.
Solution polymerization of M3 Monomer M3 (100 mg, 0.26 mmol) was dissolved in $o$-dichlorobenzene $(200 \mu \mathrm{L})$ and the system was flushed with $\mathrm{N}_{2}$ for $10 \mathrm{~min}$. Catalyst GII (2.2 mg, 1 mol \%) was added under a flow of $\mathrm{N}_{2}$ with stirring. The solution was submitted to dynamic vacuum maintained between 40-150 mbar by a regulator. The reaction mixture was heated to $45^{\circ} \mathrm{C}$ and stirred overnight. Visible gas evolution commenced immediately. After cooling to room temperature, the solution was precipitated into cold $\mathrm{MeOH}$ and collected by vacuum filtration to yield $\mathbf{P 3}$ as a light gray solid (92 $\mathrm{mg}, 99 \%)$.

Polymer P2 (bulk polymerization) ${ }^{1} \mathrm{H}$ NMR (360 $\mathrm{MHz}$, $\left.\mathrm{CDCl}_{3}\right), \delta(\mathrm{ppm}): 5.40$ (broad $\left.\mathrm{m}, 2 \mathrm{H},-\mathrm{CH}=\right), 4.21(\mathrm{t}, J=5.4$ $\left.\mathrm{Hz}, 2 \mathrm{H}, \mathrm{CH}_{2}-\mathrm{OSO}_{2}\right), 3.08\left(\mathrm{~m}, 2 \mathrm{H}, \mathrm{CH}_{2}-\mathrm{SO}_{2}-\mathrm{O}\right)$ 2.04-1.47 (m, $\left.12 \mathrm{H},-\mathrm{CH}_{2}-\right) .{ }^{13} \mathrm{C} \mathrm{NMR}\left(90 \mathrm{MHz}, \mathrm{CDCl}_{3}\right), \delta(\mathrm{ppm}): 130.0(\mathrm{~m}$, $-\mathrm{CH}=), 69.6\left(\mathrm{CH}_{2}-\mathrm{OSO}_{2}\right), 50.1\left(\mathrm{CH}_{2}-\mathrm{SO}_{2}-\mathrm{O}\right), 31.8\left(\mathrm{CH}_{2}-\right.$ $\mathrm{CH}=), 28.6,27.9,22.9\left(\mathrm{CH}_{2}-\mathrm{CH}_{2}-\mathrm{CH}_{2}\right)$.

Polymer P3 (solution polymerization) ${ }^{1} \mathrm{H}$ NMR (360 MHz, $\left.\mathrm{CDCl}_{3}\right), \delta(\mathrm{ppm}): 5.39($ broad $\mathrm{m}, 2 \mathrm{H},-\mathrm{CH}=), 4.21(\mathrm{t}, J=4.5$ $\left.\mathrm{Hz}, 2 \mathrm{H}, \mathrm{CH}_{2}-\mathrm{OSO}_{2}\right), 3.08\left(\mathrm{~m}, 2 \mathrm{H}, \mathrm{CH}_{2}-\mathrm{SO}_{2}-\mathrm{O}\right) 1.98(\mathrm{~m}, 4 \mathrm{H}$, $\left.\mathrm{CH}_{2}-\mathrm{CH}=\right), 1.85\left(\mathrm{~m}, 2 \mathrm{H}, \mathrm{CH}_{2}-\mathrm{CH}_{2} \mathrm{OSO}_{2}\right), 1.74\left(\mathrm{~m}, 2 \mathrm{H}, \mathrm{CH}_{2}-\right.$ $\left.\mathrm{CH}_{2} \mathrm{SO}_{2}-\mathrm{O}\right), 1.41-1.29\left(\mathrm{~m}, 24 \mathrm{H}, \mathrm{CH}_{2}-\mathrm{CH}_{2}-\mathrm{CH}_{2}\right) .{ }^{13} \mathrm{C} \mathrm{NMR}$ $\left(90 \mathrm{MHz}, \mathrm{CDCl}_{3}\right), \delta(\mathrm{ppm}): 130.3(\mathrm{~m},-\mathrm{CH}=), 69.7\left(\mathrm{CH}_{2}-\right.$ $\left.\mathrm{OSO}_{2}\right), 50.4\left(\mathrm{CH}_{2}-\mathrm{SO}_{2}-\mathrm{O}\right), 32.6\left(\mathrm{CH}_{2}-\mathrm{CH}=\right), 29.7,29.6$, 29.40. 29.38, 29.3, 29.1, 29.04, 28.99, 28.2, 25.4, $23.4\left(\mathrm{CH}_{2}-\right.$ $\mathrm{CH}_{2}-\mathrm{CH}_{2}$ ).

Procedure for Catalytic Hydrogenation Polymer P3 (350 $\mathrm{mg}$ ) and $10 \% \mathrm{Pd} / \mathrm{C}(17.5 \mathrm{mg})$ were combined in $\mathrm{PhCH}_{3}(20$ $\mathrm{mL})$. The heterogenous mixture was then stirred at room temperature under a hydrogen pressure of 30 bar for $72 \mathrm{~h}$. Following hydrogenation, the reaction mixture was diluted with $\mathrm{CHCl}_{3}(40 \mathrm{~mL})$ and filtered over celite. The solvent was removed under reduced pressure, yielding $\mathbf{H P 3}$ as an off-white solid $(258,73 \%) .{ }^{1} \mathrm{H}$ NMR $\left(300 \mathrm{MHz}, \mathrm{CDCl}_{3}\right), \delta$ (ppm): 4.21 $\left(\mathrm{t}, J=6.0 \mathrm{~Hz}, 2 \mathrm{H}, \mathrm{CH}_{2}-\mathrm{OSO}_{2}\right), 3.08\left(\mathrm{~m}, 2 \mathrm{H}, \mathrm{CH}_{2}-\mathrm{SO}_{2}-\mathrm{O}\right)$, $1.86\left(\mathrm{~m}, 2 \mathrm{H}, \mathrm{CH}_{2}-\mathrm{CH}_{2} \mathrm{OSO}_{2}\right), 1.74\left(\mathrm{~m}, 2 \mathrm{H}, \mathrm{CH}_{2}-\mathrm{CH}_{2} \mathrm{SO}_{2}-\mathrm{O}\right)$, 1.41-1.26 (m, 32H, $\left.\mathrm{CH}_{2}-\mathrm{CH}_{2}-\mathrm{CH}_{2}\right) .{ }^{13} \mathrm{C} \mathrm{NMR}(75 \mathrm{MHz}$, $\left.\mathrm{CDCl}_{3}\right), \delta(\mathrm{ppm}): 69.7\left(\mathrm{CH}_{2}-\mathrm{OSO}_{2}\right), 50.4\left(\mathrm{CH}_{2}-\mathrm{SO}_{2}-\mathrm{O}\right), 29.7$, 28.6, 29.54, 29.51, 29.4, 29.3, 29.2, 29.04. 29.99, 28.2, 25.4, $23.4\left(\mathrm{CH}_{2}-\mathrm{CH}_{2}-\mathrm{CH}_{2}\right)$.

\section{Results and Discussion}

\section{Monomer synthesis}

The negative neighboring group effect (NNGE) in bulk ADMET polymerization, a phenomenon in which a coordinating group in the monomer can bind the catalyst and inhibit the catalytic cycle, has been well-documented in the literature. ${ }^{39}$ This effect generally occurs when fewer than two methylene spacers separate the coordinating group and the alkene, and it has been observed for a wide variety of functional groups, including ethers, ${ }^{23}$ thioethers, ${ }^{25}$ phosphates, ${ }^{29}$ esters, ${ }^{24}$ and carbonates. ${ }^{26}$ With the aim of circumventing this potential problem, three different sulfonate ester-containing $\alpha, \omega$-diene monomers were synthesized, M1-M3, in which the sulfonate ester group was separated from the alkene with $\mathrm{m}=2,4$, and 9 methylene groups, respectively. The synthesis of M1 has been reported previously, and the procedure was readily adapted to the synthesis of M2 (Scheme 2a). ${ }^{37,40}$ Refluxing 6-bromo-1hexene in water in the presence of $\mathrm{Na}_{2} \mathrm{SO}_{3}$ generated the hexenyl sodium sulfonate intermediate, which was 
subsequently chlorinated using $\mathrm{POCl}_{3}$ to yield sulfonyl chloride 2. Finally, monomer M2 was synthesized by the condensation of 2 with 5-hexen-1-ol (Scheme 2c).

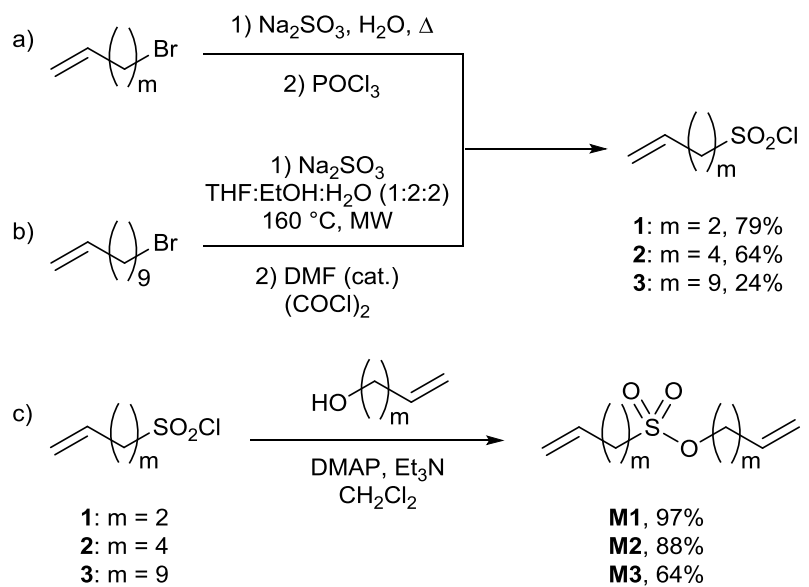

Scheme 2 Synthesis of (a) sulfonyl chlorides $\mathbf{1}$ and $2(\mathrm{~m}=2$ and $\mathrm{m}=4$, respectively), (b) sulfonyl chloride $\mathbf{3}(\mathrm{m}=9)$, (c) monomers M1-M3.

Accessing monomer M3, however, proved to be non-trivial (Scheme 2b). The first step in the original synthesis relies on the dissolution of the alkenyl sodium sulfonate salt in water as it is generated. In the case of 11-bromo-1-undecene, the resulting sodium sulfonate product exhibited extremely low solubility in water due to the longer alkenyl chains, and therefore the reaction did not reach high conversion even after refluxing for several days. Instead, a microwave procedure using a 1:2:2 mixture of THF, EtOH, and water was employed. ${ }^{41}$ The chlorination procedure using $\mathrm{POCl}_{3}$ was similarly not applicable for the synthesis of sulfonyl chloride $\mathbf{3}$, as it resulted in low and inconsistent yields and undesired byproducts. To circumvent these issues, $(\mathrm{COCl})_{2}$ with a catalytic amount of DMF was used as the chlorinating agent to form sulfonyl chloride $\mathbf{3}$ in reasonable and reproducible yields. Monomer M3 was subsequently synthesized using a condensation procedure analogous to that used for the preparation of M1 and M2.

\section{Polymer synthesis}

With the sulfonate ester-containing $\alpha, \omega$-diene monomers in hand, poly(sulfonate ester)s are accessible via ADMET polycondensation (Scheme 3). Ru-NHC alkylidene catalysts were chosen to achieve polymerization as they tend to display more functional group tolerance than Mo-based metathesis catalysts. $^{42}$ From the series of Grubbs catalysts, the second generation catalysts, both Grubbs (GII) and Hoveyda-Grubbs (HGII), were employed as their increased thermal stability is compatible with the high temperatures necessary as viscosity increases in bulk polymerizations. ${ }^{28}$

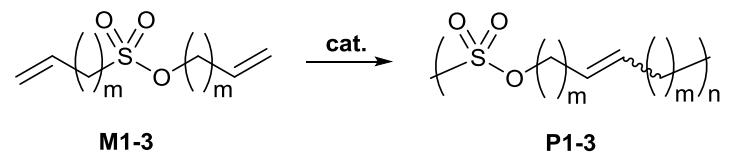

Scheme 3 ADMET polycondensation of sulfonate estercontaining $\alpha, \omega$-dienes (M1-M3) to unsaturated poly(sulfonate ester)s.

The various ADMET conditions screened for monomers M1-3 are summarized in Table 1 . In every case, $1 \mathrm{~mol} \%$ of catalyst was employed. Despite the two methylene spacers between the alkene and coordinating sulfonate group, monomer M1 did not polymerize efficiently with either catalyst. Heating M1 to $80{ }^{\circ} \mathrm{C}$ overnight in the presence of HGII, resulted in oligomers with a number-average molecular weight of $\mathrm{M}_{\mathrm{n}}=800 \mathrm{~g} / \mathrm{mol}$, as determined by NMR end-group analysis (Figure S1, Supporting Information), whereas GII appeared to be inactive and the monomer was recovered. It was possible to form polymers from monomer M2 using both catalyst HGII and GII $\left(\mathbf{M}_{\mathrm{n}}=9,24 \times\right.$ $10^{3} \mathrm{~g} / \mathrm{mol}, \emptyset=1.8$ and $\mathrm{M}_{\mathrm{n}}=7.03 \times 10^{3} \mathrm{~g} / \mathrm{mol}, \emptyset=1.7$, respectively). However, the relatively low molecular weight resulted in a sticky material that was difficult to isolate and purify by precipitation.

Consequently, our focus turned to the longer chain monomer M3. Undecenyl chains are commonly used in ADMET monomers as the competing formation of cyclic monomers is disfavored when chain lengths exceed ten atoms. ${ }^{43}$ Under identical bulk polymerization conditions, GII proved to produce polymers of higher molecular weight $\left(\mathrm{M}_{\mathrm{n}}=2.07 \times 10^{4}\right.$ $\mathrm{g} / \mathrm{mol})$ than HGII $\left(\mathrm{M}_{\mathrm{n}}=1.75 \times 10^{4} \mathrm{~g} / \mathrm{mol}\right)$. Both catalysts afforded polymers with a dispersity $(Ð)$ of 2.2 , which is consistent with the theoretical $Ð$ value of 2 for step-growth addition polymerizations. ${ }^{44}$ Based on the successful procedure reported for the polymerization of the analogous undecenyl ester-containing $\alpha, \omega$-diene, ${ }^{28}$ we also conducted the polymerization reaction under a constant flow of $\mathrm{N}_{2}$ to remove ethylene, rather than application of reduced pressure. This procedure however, carried out at $80{ }^{\circ} \mathrm{C}$ and with GII as the catalyst as before, resulted in lower molecular weights $\left(M_{n}=\right.$ $6.57 \times 10^{3} \mathrm{~g} / \mathrm{mol}$ ), and an unexpectedly high $Ð$ of 3.0.

As the reaction mixtures in the above-described bulk polymerizations became highly viscous to the point of inhibiting magnetic stirring, solution polymerization of $\mathbf{M 3}$ was also conducted under reduced pressure in $o$-dichlorobenzene, which was used as an inert solvent with low volatility. ${ }^{45}$ In this case, the vacuum was carefully maintained between 40-150 mbar by means of a regulator to mitigate the evaporation of the solvent. Gratifyingly, these conditions afforded P3 of rather high molecular weight $\left(\mathrm{M}_{\mathrm{n}}=3.66 \times 10^{4}\right)$ and low dispersity $(\bigoplus$ $=1.8$ ). The use of a solvent also made it possible to conduct the reaction at lower temperatures $\left(45^{\circ} \mathrm{C}\right)$, which likely decreases the amount of double bond migration and isomerization by GII. ${ }^{46}$

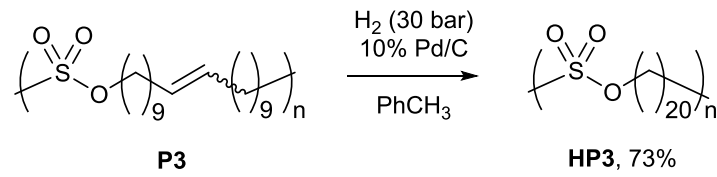

Scheme 4 Catalytic hydrogenation of $\mathbf{P 3}$ leads to the fully unsaturated poly(sulfonate ester) HP3. 
Table 1 Conditions for ADMET polycondensation of sulfonate ester-containing $\alpha, \omega$-dienes.

\begin{tabular}{|c|c|c|c|c|c|c|c|}
\hline Trial & Monomer & Conditions & Cat. (1 mol \%) & $\begin{array}{l}\mathrm{NMR}^{\mathrm{a}} \\
\mathrm{M}_{\mathrm{n}}(\mathrm{g} / \mathrm{mol})\end{array}$ & $\begin{array}{l}\mathrm{GPC}^{\mathrm{b}} \\
\mathrm{M}_{\mathrm{n}}(\mathrm{g} / \mathrm{mol})\end{array}$ & $\mathrm{M}_{\mathrm{w}}(\mathrm{g} / \mathrm{mol})$ & 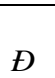 \\
\hline 2 & M1 & Various conditions & GII & - & - & - & - \\
\hline 4 & M2 & Vac, $80^{\circ} \mathrm{C}$, overnight & GII & - & $7.03 \times 10^{3}$ & $1.21 \times 10^{4}$ & 1.7 \\
\hline 5 & M3 & Vac, $80^{\circ} \mathrm{C}$, overnight & HGII & - & $1.75 \times 10^{4}$ & $3.92 \times 10^{4}$ & 2.2 \\
\hline 6 & M3 & Vac, $80^{\circ} \mathrm{C}$, overnight & GII & - & $2.07 \times 10^{4}$ & $4.54 \times 10^{4}$ & 2.2 \\
\hline
\end{tabular}

${ }^{a}$ Determined by end-group analysis where possible. ${ }^{b}$ Determined by GPC in $\mathrm{CHCl}_{3}$ vs. polystyrene standards.

Polymer P3 was exhaustively hydrogenated to access the fully unsaturated poly(sulfonate ester) HP3 (Scheme 4). Catalytic hydrogenation $\left(\mathrm{H}_{2}, \mathrm{Pd} / \mathrm{C}\right)$ provided HP3 cleanly. Figure 1a shows an overlay of the ${ }^{1} \mathrm{H}$ NMR spectra of M3, P3, and HP3. The two terminal alkene peaks converge into an internal alkene peak after polymerization, which appears to contain overlapping cis and trans signals. This alkene peak completely disappears upon hydrogenation. The elution time of the polymer by GPC does not change after hydrogenation, indicating that the sulfonate ester groups are stable to the reaction conditions (Figure $1 \mathrm{~b}$ ).

Table 2 Summary of thermal properties of P3 and HP3 as compared HDPE.

\begin{tabular}{lcccccc}
\hline & $\begin{array}{c}\mathrm{T}_{\mathrm{m}} \\
\left({ }^{\circ} \mathrm{C}\right)\end{array}$ & $\begin{array}{c}\mathrm{T}_{\mathrm{c}} \\
\left({ }^{\circ} \mathrm{C}\right)\end{array}$ & $\begin{array}{c}\mathrm{T}_{\mathrm{g}} \\
\left({ }^{\circ} \mathrm{C}\right)\end{array}$ & $\begin{array}{c}\mathrm{T}_{\mathrm{d}} \\
\left({ }^{\circ} \mathrm{C}\right)\end{array}$ & $\begin{array}{c}\Delta \mathrm{H}^{*}{ }_{\mathrm{m}} \\
(\mathrm{J} / \mathrm{g})\end{array}$ & $\begin{array}{c}\text { Cryst. }^{\mathrm{a}} \\
(\%)\end{array}$ \\
\hline P3 & 41.8 & 28.5 & -15.8 & 247.5 & 31.6 & 11 \\
HP3 & 79.7 & 68.2 & - & 261.0 & 54.6 & 19 \\
HDPE & 133.5 & 114.5 & - & 459.3 & 155.1 & 54 \\
\hline
\end{tabular}

${ }^{a}$ Percent crystallinity vs. $100 \%$ crystalline HDPE $\left(\Delta \mathrm{H}^{*}{ }_{\mathrm{m}}=\right.$ $287.3 \mathrm{~J} / \mathrm{g}){ }^{47}$

\section{Polymer properties}

The thermal properties of the higher molecular weight poly(sulfonate ester)s made from monomer M3 (both the as prepared $\mathbf{P 3}$ and the hydrogenated HP3) were studied to investigate the effects of sulfonate ester defects in the polyethylene backbone on the crystallinity and bulk properties of the material. Thermogravimetric analysis (TGA) traces of both P3 and HP3 display a sharp, rapid weight loss with an onset of decomposition $\left(\mathrm{T}_{\mathrm{d}}\right)$ at $247{ }^{\circ} \mathrm{C}$ and 261 ${ }^{\circ} \mathrm{C}$, respectively (Figure 2). A comparison with the TGA trace of HDPE of a comparable molecular weight $\left(M_{n}=2.14 \times 10^{4} \mathrm{~g} / \mathrm{mol}\right)$, which was used as a reference and does not decompose until well above $450{ }^{\circ} \mathrm{C}$, shows that both poly(sulfonate ester)s exhibit a much lower thermal stability than the corresponding hydrocarbon polymer. This observation is consistent with the decomposition of the sulfonate ester moiety by a thermally activated elimination mechanism. ${ }^{14}$ This process has been successfully employed as a decrosslinking reaction orthogonal to the generation of photocrosslinked polymers. ${ }^{48-52}$ The relatively small increase in $T_{d}$ when comparing unsaturated $\mathbf{H P 3}$ to saturated $\mathbf{P 3}$ indicates that the alkene defect does not significantly impact the thermal stability of the polymer.

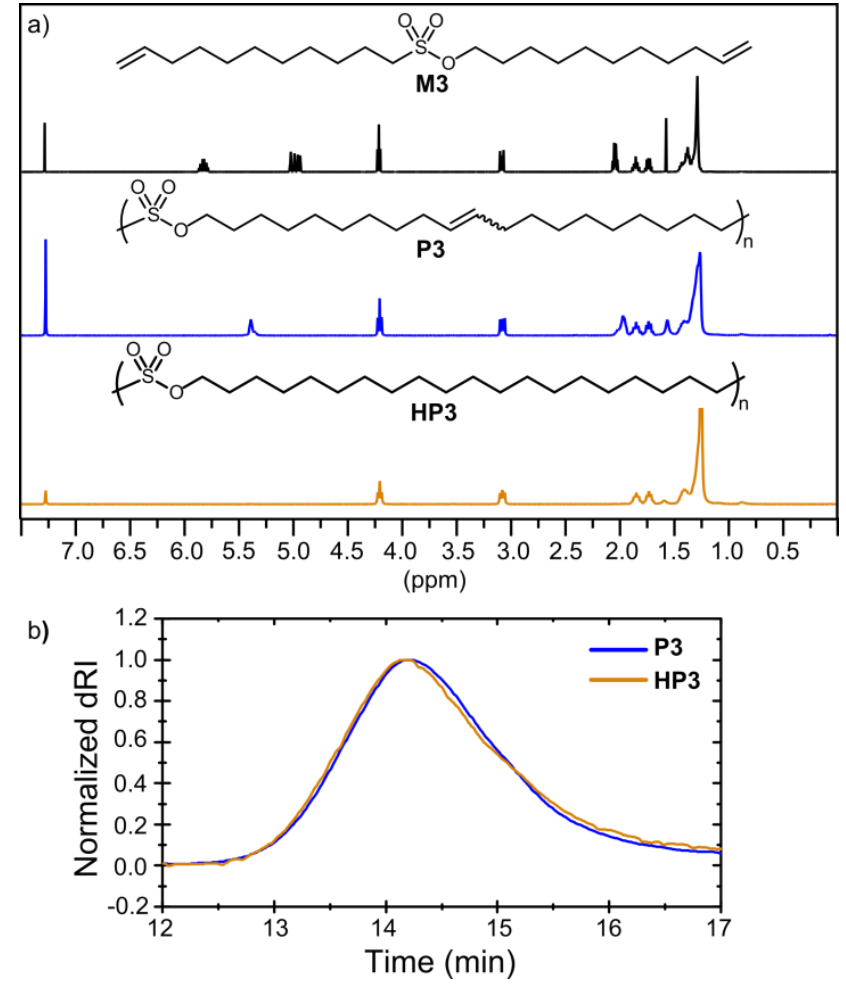

Figure 1 a) ${ }^{1} \mathrm{H}$ NMR spectra of monomer M3, unsaturated poly(sulfonate ester) P3, and saturated poly(sulfonate ester) HP3 in $\mathrm{CDCl}_{3}$. b) Overlay of GPC chromatograms in $\mathrm{CHCl}_{3}$ of the poly(sulfonate ester) before (P3) and after (HP3) catalytic hydrogenation.

Thermal transitions in P3 and HP3 were elucidated via differential scanning calorimetry (DSC) and dynamic mechanical analysis. The DSC traces of both poly(sulfonate ester)s show sharp endotherms that are diagnostic of crystalline to melt transitions (Figure 3). As expected, both the double bonds and sulfonate ester moieties act as defects influencing the crystallization of the polymers, resulting in a decrease in the melting temperature from $134{ }^{\circ} \mathrm{C}$ (HDPE) to $80{ }^{\circ} \mathrm{C}(\mathbf{H P 3})$ or $42{ }^{\circ} \mathrm{C}$ (P3, Table 2). A corresponding decrease of the heat of fusion is also observed, indicative of a decrease in crystallinity (Table 2). We note that no glass transition could be discerned in the DSC traces above $-80{ }^{\circ} \mathrm{C}$. The DMA trace of a solution cast film $\left(\mathrm{PhCH}_{3}\right)$ of $\mathbf{P 3}$ (Figure S2, Supporting Information), 
however, clearly reveals a $\mathrm{T}_{\mathrm{g}}$ at $-15.8{ }^{\circ} \mathrm{C}$, where the material transitions from a glassy state with a tensile storage modulus $E^{\text {, }}$ of $1228 \mathrm{MPa}$ at $-100{ }^{\circ} \mathrm{C}$ to a rubbery plateau with a roomtemperature $E$ ' of $85 \mathrm{MPa}$. Unfortunately, films of HP3 were too brittle for mechanical testing.

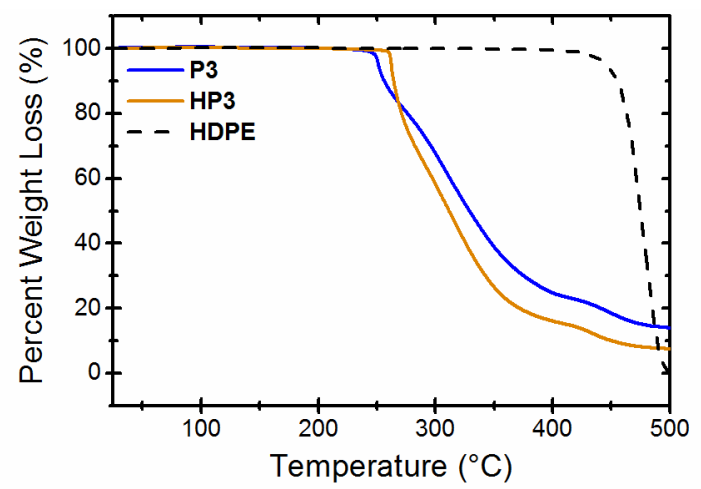

Figure 2 Thermogravimetric analysis traces of P3, HP3, and HDPE, which was used as a reference. Samples were heated at a rate of $10^{\circ} \mathrm{C} / \mathrm{min}$ under nitrogen.

In their study on long-chain aliphatic polyesters, Mecking et $a l .{ }^{10}$ found that the ester groups are likely included in the crystalline phase as packing defects, as has been demonstrated for methyl-substituted polyethylene by Wagener and coworkers. $^{20,53}$ A comparison of the literature data suggests that an increase of the fraction of methyl groups has a more significant influence on the melting point of the corresponding polymer than an increase of the ester content. In addition, an increase of the methyl content was found to cause a change of the morphology from an orthorhombic to a hexaganol crystal structure, ${ }^{53}$ whereas the orthorhombic structure was maintained in long-chain polyesters. ${ }^{10}$ Mecking and coworkers propose two possible explanations for this effect; the decreased steric hindrance of the ester moiety versus the methyl group, and the influence of dipole-dipole interactions between ester groups on the packing. We surmised that the investigation of the present long-chain poly(sulfonate ester)s might contribute to a better understanding of this situation, as sulfonate esters are also capable of dipole-dipole interactions but are more sterically demanding than carbonate esters due to their tetrahedral geometry.

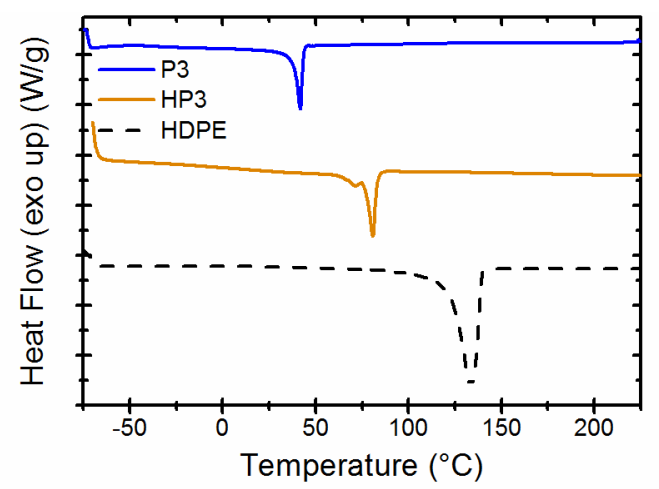

Figure 3 Comparison of the second heating curves from the DSC of P3, HP3, and HDPE. All experiments were performed at a heating/cooling rate of $10{ }^{\circ} \mathrm{C} / \mathrm{min}$.
To further understand the effect of the sulfonate ester defect on morphology, melt-processed films of the materials were analyzed via small- and wide-angle X-ray scattering (SAXS and WAXS, respectively) (Figure 4). For HDPE, the sharp scattering maxima, centered at $\mathrm{q} \sim 15$ and $16.7 \mathrm{~nm}^{-1}$ in the WAXS spectra, are associated with the (110) and (200) planes of the orthorhombic unit cell. ${ }^{54-58}$ The corresponding scattering maxima observed for HP3 and $\mathbf{P 3}$ are centered at lower $\mathrm{q}$ values, which indicates an increased lattice constant and, as expected, a lower degree of crystallinity. In the case of P3, only the first scattering peak is evident. These crystalline peaks also overlap with a significant amorphous halo. The shifts in the WAXS spectra between HDPE, and P3 and HP3 were also confirmed by IR spectroscopy (Figure S3, Supporting Information). The methylene rocking and scissoring vibrations indicative of an orthorhombic crystal structure, at $719 / 730 \mathrm{~cm}^{-1}$ and $1463 / 1472 \mathrm{~cm}^{-1}$ respectively, are not present in the spectra of $\mathbf{P 3}$ and HP3. Thus, it appears that the inclusion of sulfonate esters in the polymer backbone causes a significant disturbance on the crystal structure of the present polymers, which does not mirror the abovediscussed behavior of long-chain aliphatic polyesters. ${ }^{10}$
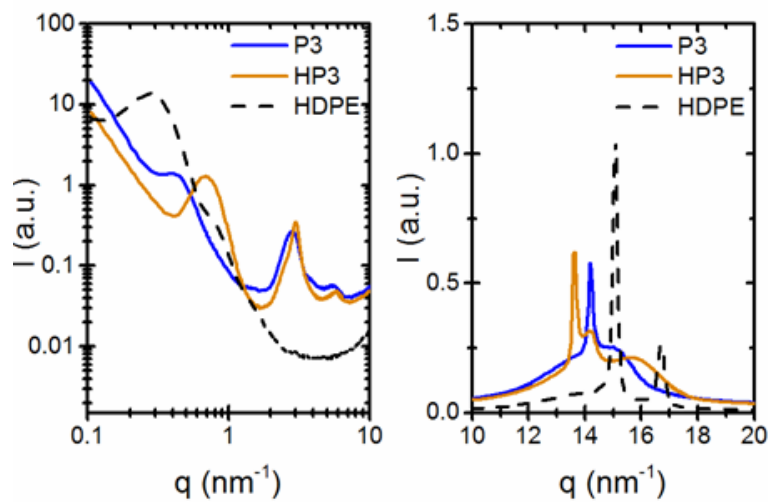

Figure 4 a) SAXS and b) WAXS spectra of films of P3, HP3, and HDPE. In all cases films were melt-processed and quenched at low temperature.

A distinct feature of the SAXS spectra of P3 and HP3 is the scattering maxima at $\mathrm{q} \sim 3$ and $6 \mathrm{~nm}^{-1}$. The center positions of these scattering maxima correspond to a separation length of approximately $2 \mathrm{~nm}$ and suggest a highly correlated arrangement of clusters of sulfonate ester groups segregated from the polymer phase, possibly owing to dipole-dipole interactions. This implies a rather well-defined folding of the polymer chains. Similar structural features have been observed for precise ion-containing copolymers based on polyethylene and have been attributed to a regular layerlike packing of ion-containing clusters. ${ }^{59}$ In our data, the presence of crystallites is more evident than in other studies in which data were collected at temperatures exceeding the $T_{m}$ of the polymer. In HP3 an increased proximity of clusters is suggested as compared to P3, as the peaks are sharper and centered at larger $q$ values.

The features of the SAXS spectra at low angles primarily originate from the scattering contrast found between the crystalline and amorphous domains. The center of the so-called crystalline peak is usually interpreted as the measure of the average distance between crystalline domains. HDPE shows a separation length of approximately $21 \mathrm{~nm}$, whereas that length is smaller for HP3 at $\sim 7.8$ $\mathrm{nm}$. The crystalline peak of $\mathbf{P 3}$ is not as distinct as in the case of the samples above. This is likely due to the decreased level of crystallinity caused by additional unsaturation in the backbone. It is clear from the analysis of the thermal, mechanical, and 
morphological properties, that while the inclusion of sulfonate ester groups does disturb the bulk properties as compared to HDPE, this material fits in nicely with the series of polyethylene-like polymers reported to date.

\section{Conclusions}

The synthesis of a new class of polymers, poly(sulfonate ester)s, has been achieved. Sulfonate ester-containing $\alpha, \omega-$ dienes expand the library of functional monomers for ADMET polymerization. The long-chain monomer M3 and its sulfonyl chloride precursor, necessary to achieve high molecular weights, were synthesized for the first time with the aid of a microwave reactor. Solution polymerization with GII at high concentrations under reduced pressure proved to be the optimal conditions for polymerization. Comparison of the thermal properties of these materials demonstrates the ease of thermal degradation of poly(sulfonate ester)s as well as the effects of the introduced functional group on crystallinity. Access to this previously unexplored class of polymers elaborates on our understanding of what materials may constitute "degradable polyethylene." Due to the highly versatile nature of olefin metathesis, studying the metathesis activity of sulfonate estercontaining $\alpha, \omega$-dienes also leaves open the opportunity to tune material properties through the use of a wide variety of comonomers.

\section{Acknowledgements}

This work was supported by the European Research Council (ERC-2011-AdG 291490-MERESPO).

The authors thank Mr. Felix Fehr for NMR analysis acquired on a $500 \mathrm{MHz}$ spectrometer and Mr. Fredy Nydegger for mass spectrometry, both of the University of Fribourg chemistry department analytical services. The authors also thank Dr. Lucas Montero for fruitful discussion on ADMET polymerization.

\section{Notes and references}

${ }^{a}$ Adolphe Merkle Institute, University of Fribourg, Rte de l'Ancienne Papeterie, 1723 Marly, Switzerland. E-mail: yoan.simon@unifr.ch.

Electronic Supplementary Information available. See DOI: $10.1039 / \mathrm{b} 000000 \mathrm{x} /$

1. J. Boor, Jr., Ziegler-Natta Catalysts and Polymerizations, Academic Press, New York, 1979.

2. P. K. Roy, M. Hakkarainen, I. K. Varma and A.-C. Albertsson, Environ. Sci. Technol., 2011, 45, 4217-4227.

3. G. Swift, R. Baciu and E. Chiellini, in Polymer Degradation and Performance, eds. M. C. Celina, J. S. Wiggins and N. C. Billingham, American Chemical Society, Washington, DC, 2009, vol. 1004, pp. 2-16.

4. M. C. Sobieraj and C. M. Rimnac, J. Mech. Behav. Biomed. Mater., 2009, 2, 433-443.

5. NL Pat., NL20001014608 20000310, 2001.

6. C.-C. Chang and T. Emrick, Macromolecules, 2014, 47, 1344-1350.

7. W. J. Bailey, V. K. Kuruganti and J. S. Angle, ACS Symp. Ser., 1990, 433, 149-160.
8. M. L. Robertson, K. Chang, W. M. Gramlich and M. A. Hillmyer, Macromolecules, 2010, 43, 1807-1814.

9. A. Pucci, F. Signori, R. Bizzarri, S. Bronco, G. Ruggeri and F. Ciardelli, J. Mater. Chem., 2010, 20, 5843-5852.

10. P. Ortmann and S. Mecking, Macromolecules, 2013, 46, 7213-7218.

11. M. G. Menges, J. Penelle, C. Le Fevere de Ten Hove, A. M. Jonas and K. Schmidt-Rohr, Macromolecules, 2007, 40, 8714-8725.

12. F. Stempfle, P. Ortmann and S. Mecking, Macromol. Rapid Commun., 2013, 34, 47-50.

13. C. Le Fevere de Ten Hove, J. Penelle, D. A. Ivanov and A. M. Jonas, Nat. Mater., 2004, 3, 33-37.

14. E. J. Corey, G. H. Posner, R. F. Atkinson, A. K. Wingard, D. J. Halloran, D. M. Radzik and J. J. Nash, J. Org. Chem., 1989, 54, 389393.

15. P. W. C. Barnard and R. E. Robertson, Can. J. Chem., 1961, 39, 881888.

16. H. Mutlu, L. Montero de Espinosa and M. A. R. Meier, Chem. Soc. Rev., 2011, 40, 1404-1445.

17. P. Atallah, K. B. Wagener and M. D. Schulz, Macromolecules, 2013, 46, 4735-4741.

18. M. Scholl, S. Ding, C. W. Lee and R. H. Grubbs, Org. Lett., 1999, 1, 953-956.

19. S. B. Garber, J. S. Kingsbury, B. L. Gray and A. H. Hoveyda, J. Am. Chem. Soc., 2000, 122, 8168-8179.

20. J. A. Smith, K. R. Brzezinska, D. J. Valenti and K. B. Wagener, Macromolecules, 2000, 33, 3781-3794.

21. G. Rojas, E. B. Berda and K. B. Wagener, Polymer, 2008, 49, 29852995.

22. G. Rojas and K. B. Wagener, Macromolecules, 2009, 42, 1934-1947.

23. K. B. Wagener and K. Brzezinska, Macromolecules, 1991, 24, 52735277.

24. J. T. Patton, J. M. Boncella and K. B. Wagener, Macromolecules, 1992, 25, 3862-3867.

25. J. E. O'Gara, J. D. Portmess and K. B. Wagener, Macromolecules, 1993, 26, 2837-2841.

26. K. B. Wagener and J. T. Patton, Macromolecules, 1993, 26, 249-253.

27. J. D. Portmess and K. B. Wagener, J Poly Sci Part A Polym Chem, 1996, 34, 1353-1357.

28. A. Rybak and M. A. R. Meier, ChemSusChem, 2008, 1, 542-547.

29. F. Marsico, M. Wagner, K. Landfester and F. R. Wurm, Macromolecules, 2012, 45, 8511-8518.

30. D. Steiger, M. Ehrenstein, C. Weder and P. Smith, Macromolecules, 1998, 31, 1254-1260.

31. D. Steiger, C. Weder and P. Smith, Macromolecules, 1999, 32, 53915398.

32. D. Steier, T. Tervoort, C. Weder and P. Smith, Macromol. Rapid Comm., 2000, 21, 405-422.

33. N. Spassky, M. Sepulchre and P. Sigwalt, in Handbook of Polymer Synthesis Part B, ed. H. R. Kricheldorf, Marcel Dekker, Inc., New York, 1992, ch. 16, pp. 991-1076.

34. A. Kultys, in Encyclopedia of Polymer Science and Technology, John Wiley \& Sons, Inc., 2002, DOI: 10.1002/0471440264.pst355.pub2.

35. S. Hashimoto, T. Yamashita and M. Kaneda, Polym. J., 1974, 6, 238241.

36. Y. C. Simon and E. B. Coughlin, J. Polym. Sci., Part A: Polym. Chem., 2010, 48, 2557-2563. 
37. A. Le Flohic, C. Meyer and J. Cossy, Tetrahedron, 2006, 62, 90179037.

38. G. Friedmann, C. Gandon, G. Boiron, S. Staveris and A. Bouilloux, European Polymer Journal, 1998, 34, 351-161.

39. K. B. Wagener, K. Brzezinska, J. D. Anderson, T. R. Younkin, K. Steppe and W. DeBoer, Macromolecules, 1997, 30, 7363-7369.

40. US Pat., US20120094897, 2012.

41. S. O. Alapafuja, S. P. Nikas, V. G. Shukla, I. Papanastasiou and A. Makriyannis, Tetrahedron Lett., 2009, 50, 7028-7031.

42. F. C. Courchay, J. C. Sworen and K. B. Wagener, Macromolecules, 2003, 36, 8231-8239.

43. J. E. Schwendeman, A. C. Church and K. B. Wagener, Adv. Synth. Catal., 2002, 344, 597-613.

44. K. B. Wagener, J. M. Boncella and J. G. Nel, Macromolecules, 1991, 24, 2649-2657.

45. S. A. Sydlik, P. A. Delgado, S. Inomata, B. VanVeller, Y. Yang, T. M. Swager and K. B. Wagener, J Polym Sci Pol Chem, 2013, 51, 1695-1706.

46. P. A. Fokou and M. A. R. Meier, J. Am. Chem. Soc., 2009, 131, 1664-1665.

47. F. M. Mirabella and A. Bafna, J. Polym. Sci., Part B: Polym. Phys., 2002, 40, 1637-1643.

48. Y.-D. Shin, A. Kawaue, H. Okamura and M. Shirai, Polym. Degrad. Stabil., 2004, 86, 153-158.

49. Y.-D. Shin, A. Kawaue, H. Okamura and M. Shirai, React. Funct. Polym., 2004, 61, 293-302.

50. H. Okamura, Y. Tajima and M. Shirai, J. Photopolym. Sci. Technol., 2005, 18, 715-718.

51. T. Ohba, K. Suyama and M. Shirai, J. Photopolym. Sci. Technol., 2006, 19, 709-712.

52. H. Okamura, Y. Tajima, T. Ohba, K. Suyama and M. Shirai, J. Photopolym. Sci. Technol., 2007, 20, 303-306.

53. J. C. Sworen, J. A. Smith, K. B. Wagener, L. S. Baugh and S. P. Rucker, J. Am. Chem. Soc., 2003, 125, 2228-2240.

54. D. C. Bassett, S. Block and G. J. Piermarini, J. Appl. Phys., 1974, 45, 4146-4150.

55. M. Yasuniwa, R. Enoshita and T. Takemura, Jpn J Appl Phys, 1976, 15, 1421-1428.

56. T. Yamamoto, H. Miyaji and K. Asai, Jpn J Appl Phys, 1977, 16, 1891-1898.

57. S. Rastogi, L. Kurelec and P. J. Lemstra, Macromolecules, 1998, 31, $5022-5031$.

58. C. W. Bunn, Trans. Faraday Soc., 1939, 35, 482-491.

59. C. F. Buitrago, J. E. Jenkins, K. L. Opper, B. S. Aitken, K. B. Wagener, T. M. Alam and K. I. Winey, Macromolecules, 2013, 46, 9003-9012. 